\title{
Comparison of outcome in medical versus expectant management in unruptured tubal pregnancy with $\beta$-hCG 1000-3000 IU/L
}

\author{
Sidra Arshad ${ }^{1 *}$, Sonia Andeel², Samia Asghar, Sana Hafeez ${ }^{1}$, Sana Asghar ${ }^{4}$, Naheed Fatima²
}

\begin{abstract}
${ }^{1}$ Department of Obstetrics and Gynecology, Civil Hospital, Bahawalpur, Pakistan
${ }^{2}$ Department of Obstetrics and Gynecology, Unit-2, Bahawal Victoria Hospital, Bahawalpur, Pakistan

${ }^{3}$ Department of Obstetrics and Gynecology, Jubilee Female Hospital, Bahawalpur, Pakistan

${ }^{4}$ Department of Obstetrics and Gynecology, Tehsil Head Quarter Hospital, Yazman, Pakistan
\end{abstract}

Received: 29 April 2020

Accepted: 05 May 2020

\section{*Correspondence:}

Dr. Sidra Arshad,

E-mail: sid.20m@hotmail.com

Copyright: (c) the author(s), publisher and licensee Medip Academy. This is an open-access article distributed under the terms of the Creative Commons Attribution Non-Commercial License, which permits unrestricted non-commercial use, distribution, and reproduction in any medium, provided the original work is properly cited.

\begin{abstract}
Background: Ectopic pregnancy (EP) is an important cause of maternal morbidity as well as mortality in the 1 st trimester. This study was done to compare outcome in medical versus expectant management in patients with unruptured tubal pregnancy having $\beta$-hCG 1000-3000 IU/L.

Methods: In this randomized controlled trial, 82 (41 in each group) women with tubal ectopic pregnancy (TEP) having $\beta$-hCG levels between 1000-3000 IU/L and 18 to 40 years of age were enrolled. Women having non-tubal pregnancy, ruptured ectopic pregnancy, heterotopic pregnancy, hypersensitivity to methotrexate were excluded. Included women were randomly assigned to either Group-A (expectant management) or Group-B (medical management). Outcome was measured after one week and considered successful if patient had $\beta$-hCG levels negligible i.e. $<10 \mathrm{IU} / \mathrm{L}$ and complete resolution on ultrasonography (absence of adnexal mass, pelvic free fluid, gestational sac).

Results: Overall mean age was $30.65 \pm 6.37$ years. The mean gestational age in Group-A was $7.12 \pm 2.12$ weeks and $7.63 \pm 2.41$ weeks in Group-B. The mean $\beta$-hCG levels in Group-A was 1984.63 \pm 515.81 IU/L and 1937.33 \pm 519.68 IU/L in Group-B. Outcome was successful in $90.24 \%$ in Group-A and 63.41\% in Group-B (p-value=0.004).

Conclusions: Expectant management is associated with better outcome as compared to medical management in tubal ectopic pregnancy having $\beta$-hCG between 1000-3000 IU/L.
\end{abstract}

Keywords: Ectopic pregnancy, Expectant, Methotrexate, Resolution

\section{INTRODUCTION}

When fertilized ovum is implanted outside the uterine cavity, that pregnancy is described as ectopic pregnancy (EP). ${ }^{1} \mathrm{EP}$ is an important cause of maternal mortality and morbidity in the $1^{\text {st }}$ trimester. ${ }^{2}$ Incidence of EP varies from 1-2 per 100 pregnancies globally. ${ }^{3}$ Delays in diagnosis and treatment can make EP an acute emergency. On the other hand, timely diagnosis and treatment is observed to minimize the risk of maternal morbidity as well as mortality. ${ }^{4,5}$ Whenever a woman is presented with bleeding per vagina during pregnancy, it is recommended that EP should always be ruled out. ${ }^{6}$

Availability of high resolution transvaginal ultrasonography (TVS) along with rapid immunoassay of serum hCG have allowed clinicians to early diagnosis of pregnancy location. ${ }^{7}$ More than $90 \%$ of EP are visualized employing TVS. ${ }^{8}$ In the past, EP was considered to be an emergency and life threatening condition needing emergency surgeries but thanks to advancement in the recent decades, non-surgical options are now also offered 
to women having EP. Major benefit of non-surgical options regarding management of EP includes avoidance of potential iatrogenic injury to fallopian tubes. ${ }^{8}$

Presently, laparoscopy is not seen as a gold standard for diagnosing EP while medical and expectant management options for EP have become a topic of interest for researchers around the world. ${ }^{9}$ Selecting suitable group of women with EP regarding non-surgical options has gained so much importance in the recent years. Trio D et al in their study found success rate of $88 \%$ employing expectant management among women having EP with $\beta$ hCG $<1000 \mathrm{IU} / \mathrm{L}$ whereas Dhar $\mathrm{H}$ et al noted $65 \%$ success rate following single dose of methotrexate (MTX). ${ }^{10,11}$

This study aimed to analyse whether single dose of MTX or expectant management is associated with successful outcome in un-ruptured tubal ectopic pregnancy (TEP) having $\beta$-hCG between $1000-3000$ IU/L so that the better modality should be advised for these particular women. Data regarding management of un-ruptured TEP with $\beta$ hCG between $1000-3000$ IU/L is scarce while no local data exists in our local population. This study would also give better management plan for our population in order to avoid tubal injury and improve fertility outcome.

\section{METHODS}

This randomized controlled trial was conducted at the department of obstetrics and gynecology, Civil Hospital, Bahawalpur, Pakistan from January to August 2018. Approval from institutional ethical committee was sough.

A sample size of 82 (41 in each group) was calculated, considering significance level $(\alpha)$ as $5 \%$, power $(1-\beta)$ as $80 \%$ and anticipated population proportion $(\mathrm{P} 1)$ as $88.0 \%$ and anticipated population proportion $(\mathrm{P} 2)$ as $65.0 \% .^{10,11}$ A total of 82 women (41 in each group) adopting nonprobability, consecutive sampling were recruited.

\section{Inclusion criteria}

- Women with TEP having $\beta$-hCG levels between 1000-3000 IU/L, size of ectopic mass $<4 \mathrm{~cm}$ and aged 18-40 years. TEP was labeled as any pregnancy within the fallopian tubes and were diagnosed on ultrasonography as presence of a thick, brightly echogenic, ring like structure is located outside the uterus, with a gestational sac without cardiac activity, having $\beta$-hCG between 1000-3000 IU/L.

\section{Exclusion criteria}

- Patients with ruptured ectopic pregnancy assessed on ultrasound, hemodynamically unstable patients, presence of fetal cardiac activity, coexistent viable intrauterine pregnancy (heterotopic pregnancy), hepatic or renal failure, known hypersensitivity to
MTX or those who were unwilling to be part of this study.

After taking informed, written consent from every women, they were presented to pick up a slip from mixed up slips (half had letter ' $A$ ' and half ' $B$ ') and then patient was placed in that respective group. Group-A had women with expectant management while in Group-B, medical management (single intramuscular injection of MTX in a dose of $50 \mathrm{mg} / \mathrm{m}^{2}$ ) was done. Outcome was measured after one week and was considered successful if patient had $\beta$-hCG levels negligible i.e. <10 IU/L and complete resolution on ultrasonography (absence of adnexal mass, pelvic free fluid, gestational sac) and was considered unsuccessful if patient had $\beta$-hCG levels >3000 IU/L and no complete resolution.

\section{Statistical analysis}

Statistical analysis was conducted by SPSS version 20 . Age, gestational age and $\beta$-hCG levels were represented as mean \pm SD. Outcome (successful/unsuccessful) was presented by frequency and percentages. Comparison between the groups with respect to outcome (successful/unsuccessful) was analyzed by Chi-square. Stratification for age, gestational age and $\beta$-hCG levels were also done among both groups applying chi-square test, considering $\mathrm{p}$-value $<0.05$ as significant.

\section{RESULTS}

Overall, age range was $18-40$ years with mean of $30.65 \pm 6.37$ years. Mean age in Group-A was $30.90 \pm 5.95$ years and 30.51 \pm 6.53 years in Group-B. Most women, 47 $(57.32 \%)$ were between 31 to 40 years of age. Overall, mean gestational age was $7.44 \pm 2.27$ weeks. The mean gestational age in Group-A was 7.12 \pm 2.12 weeks and in Group-B 7.63 \pm 2.41 weeks. Majority, 42 (51.22\%) patients were $>6$ weeks of gestation. Overall, mean $\beta$ hCG levels were noted to be $1965.45 \pm 517.89 \mathrm{IU} / \mathrm{L}$. The mean $\beta$-hCG levels in Group-A was 1984.63+515.81 and in Group-B was 1937.33 \pm 519.68 IU/L. Table 1 compares characteristics of patients between both groups.

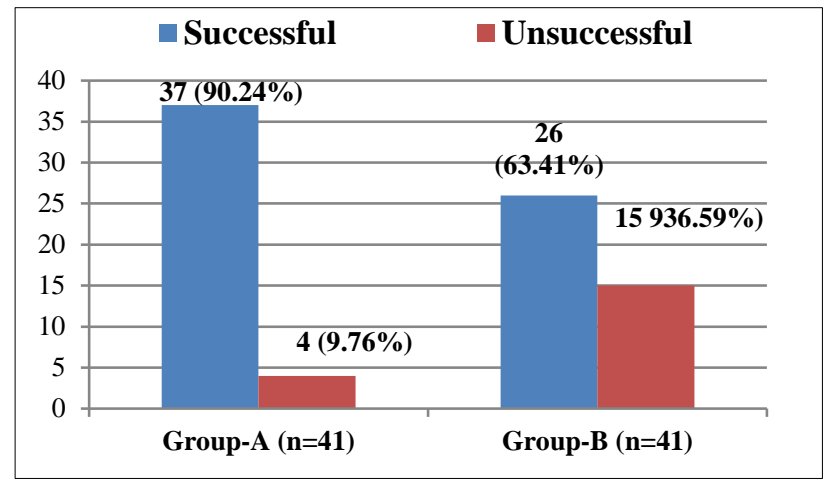

p-value $=0.004$.

Figure 1: Comparison of outcome between both study groups $(\mathbf{n}=\mathbf{8 2})$. 
Table 1: Characteristics of patients between both study groups $(\mathrm{n}=\mathbf{8 2})$.

\begin{tabular}{|c|c|c|c|c|}
\hline Characteristics & & Group-A (n=41) & Group-B $(n=41)$ & p-value \\
\hline \multirow{2}{*}{ Age groups (years) } & 18 to 30 & $18(43.90 \%)$ & $17(41.46 \%)$ & \multirow{2}{*}{0.8233} \\
\hline & $>30$ to 40 & $23(56.10 \%)$ & $24(58.54 \%)$ & \\
\hline \multirow{2}{*}{$\begin{array}{l}\text { Gestational age } \\
\text { (weeks) }\end{array}$} & $\leq 6$ weeks & $19(46.34 \%)$ & $21(51.22 \%)$ & \multirow{2}{*}{0.6586} \\
\hline & $>6$ weeks & $22(53.66 \%)$ & $20(48.78 \%)$ & \\
\hline \multirow{2}{*}{$\beta$-hCG levels } & $1000-2000$ & $25(60.98 \%)$ & $23(56.10 \%)$ & \multirow{2}{*}{0.6539} \\
\hline & $>2000-3000$ & $16(30.02 \%)$ & $18(43.90 \%)$ & \\
\hline
\end{tabular}

Table 2: Stratification of outcome with respect to patient's characteristics between both study groups $(\mathrm{n}=82)$.

\begin{tabular}{|c|c|c|c|c|c|c|}
\hline \multirow{3}{*}{\multicolumn{2}{|c|}{ Characteristics }} & \multicolumn{2}{|c|}{ Group A $(n=41)$} & \multicolumn{2}{|c|}{ Group B $(n=41)$} & \multirow{3}{*}{ p-valuc } \\
\hline & & \multicolumn{2}{|l|}{ Outcome } & \multicolumn{2}{|l|}{ Outcome } & \\
\hline & & Successful & Unsuccessful & Successful & Unsuccessful & \\
\hline \multirow{2}{*}{$\begin{array}{l}\text { Age groups } \\
\text { (years) }\end{array}$} & $18-30$ & $16(88.89 \%)$ & $02(11.11 \%)$ & $12(70.59 \%)$ & $05(29.41 \%)$ & 0.176 \\
\hline & $>30-40$ & $21(91.30 \%)$ & $02(8.70 \%)$ & $14(58.33 \%)$ & $10(41.67 \%)$ & 0.010 \\
\hline \multirow{2}{*}{$\begin{array}{l}\text { Gestational } \\
\text { age (weeks) }\end{array}$} & $\leq 6$ & $18(94.74 \%)$ & $01(5.26 \%)$ & $18(85.71 \%)$ & $03(14.29 \%)$ & 0.342 \\
\hline & $>6$ & $19(86.36 \%)$ & $03(13.64 \%)$ & $08(40.0 \%)$ & $12(60.0 \%)$ & 0.002 \\
\hline \multirow{2}{*}{$\begin{array}{l}\beta \text {-hCG } \\
\text { levels }\end{array}$} & $1000-2000$ & $24(96.0 \%)$ & $01(4.0 \%)$ & $12(52.17 \%)$ & $11(47.83 \%)$ & 0.000 \\
\hline & $>2000-3000$ & $13(81.25 \%)$ & $03(18.75 \%)$ & $14(77.78 \%)$ & $04(22.22 \%)$ & 0.803 \\
\hline
\end{tabular}

There was $\beta$-hCG levels negligible i.e. $<10 \mathrm{IU} / \mathrm{L}$ and complete resolution on ultrasonography (absence of adnexal mass, pelvic free fluid, gestational sac) within one week in 37 (90.24\%) patients in Group-A (expectant management) while in Group-B (medical management), it was noted in $26(63.41 \%)$, as shown in Figure 1.

Stratification of outcome with respect to age groups, gestational age and $\beta$-hCG levels in both groups is shown in Table 2. Statistically significant difference among both groups between 31-40 years of age, >6 weeks of gestational age and $\beta$-hCG levels between 1000-2000 IU/L were noted ( $\mathrm{p}$-value $<0.05$ ).

\section{DISCUSSION}

Rising incidence of EP is partially credited to improvement is early diagnosis of EP in the recent decades. EPs which were resulting into tubal abortions or complete spontaneous reabsorption are not being detected due to improvement in diagnostic tools. ${ }^{12,13}$ Many researchers around the world are now questioning needless use of surgical or medical intervention and advocating expectant management is selective subgroups. Differentiating between those individuals who are going through spontaneous resolution and those who are undergoing proliferative EPs can be challenging.

Lund $\mathrm{J}$, was the first who shared his experience of expectant management among women suspected with EP. ${ }^{14}$ Natural course of many early EPs are thought to be self-limiting ending up as tubal abortions or reabsorption which could be the reason that expectant management has come up a valid choice for the resolution of EP. Close monitoring of serum hCG levels is essential for the detection of inappropriately falling serum hCG concentration. $^{15,16}$ Exact criteria for the therapeutic intervention has not been laid down so far. Very little work exist exploring serum hCG dynamics during spontaneous resolution of EP. Watchful waiting among selected subgroups of women having EP has been shown to be a good alternative option for the management of those cases while not many randomized controlled trails exist in this regard. ${ }^{15,17}$ In this study, outcome was successful in $90.24 \%$ in Group-A (expectant management) and $63.41 \%$ in Group-B (medical management) while the difference was of statistical significance (p-value $=0.004)$.

Initial $\beta$-HCG level is taken as the best predictor of success in medical management of EP. Lipscomb GH noted efficacy of single dose of MTX exceeding 90\% when $\beta$-hCG levels were below $5000 \mathrm{mlU} / \mathrm{mL}$ but that success rate declined below $80 \%$ when $\beta$-hCG levels were between 5000 to $10000 \mathrm{mlU} / \mathrm{mL}$. ${ }^{18}$ With $\beta$-hCG levels more than $15000 \mathrm{mlU} / \mathrm{L}$, success rate was noted to drop below $80 \%$. A local study conducted by Mahboob U et al noted success rate of $80 \%$ adopting single dose of MTX with initial levels of $\beta-\mathrm{hCG}$ at $5000 \mathrm{mlU} / \mathrm{mL} .{ }^{19}$

Researchers from UK noted expectant management in TEP to eliminate need for medical or surgical management in more than $1 / 3^{\text {rd }}$ of the patients with minimum risk of adverse outcomes. ${ }^{20}$ Others have noted success rate of $96 \%$ employing expectant management of EP when $\beta$-hCG levels were below 175 IU/L. ${ }^{15}$ Utilization of TVS for monitoring of EPs chosen for expectant management has shown to be an effective for the recognition of those who would most likely resolve 
spontaneously. A trial done by Cacciatore B et al noted $55 \%$ of cases managed using expectant management approach were having decrease in size of EP by $3^{\text {rd }}$ day and $84 \%$ by $7^{\text {th }}$ day. ${ }^{21}$ Predictive sensitivity and specificity for spontaneous resolution of EP in terms of decrease in size were found to be $84 \%$ and $100 \%$ on $7^{\text {th }}$ day respectively. ${ }^{21}$

In comparison to medical management, expectant management has also been found to minimize the risk of rupture and sever intra-abdominal bleeding among women having EP. ${ }^{22}$ Expectant management does not have any kind of side effect which are frequently seen with medical management. Hajenius $\mathrm{P}$ et al noted $61 \%$ of their patients taking MTX experienced side effects or complications. ${ }^{23}$ Medical management has also been seen to limit social functioning in women with EP. ${ }^{24}$

One of the limitations of the current study was that we were unable to note fertility outcomes following expectant and medical management among out study participants.

\section{CONCLUSION}

Expectant management is associated with better outcome as compared to medical management in tubal ectopic pregnancy having $\beta$-hCG between 1000-3000 IU/L. Expectant management should be preferred in women with tubal ectopic pregnancy having $\beta$-hCG between 1000-3000 IU/L in order to avoid tubal injury.

\section{ACKNOWLEDGMENTS}

Authors would like to thank to M. Aamir (Bahawalpur, Pakistan) for his assistance in statistical analysis of this research.

Funding: No funding sources Conflict of interest: None declared

Ethical approval: Not Required

\section{REFERENCES}

1. Ali SK, Ali AA, Soomar SM. Diagnosis and management of ectopic pregnancy-a basic view through literature. Crit Care Obst Gyne. 2019;5(2):7.

2. Meena N, Bairwa R, Sharma S. Study of ectopic pregnancy in a tertiary care centre. Int $\mathbf{J}$ Reprod Contracept Obstet Gynecol. 2020;9(1):212-5.

3. Jurkvic D. Diagnosis and management of ectopic pregnancy. British Med J. 2011;342:3397.

4. Shaikh NB, Shaikh S, Shaikh F. A clinical study of ectopic pregnancy. J Ayub Med Coll Abbottabad. 2014;26(2):178-81.

5. Hakim H, Yaich R, Halouani S, Jouou S, Arfaoui R, Rachdi R. Non-surgical management of ectopic pregnancies. J Gynecol Oncol. 2019;2(2):1013.

6. ACOG Practice Bulletin No. 193 Summary: Tubal Ectopic Pregnancy. Obstet Gynecol. 2018;131:613-5.
7. Barash JH, Buchanan EM, Hillson C. Diagnosis and management of ectopic pregnancy. Am Fam Physician. 2014;90:34-40.

8. Van Mello NM, Mol F, Opmeer BC, Ankum WM, Barnhart K, Coomarasamy A, et al. Diagnostic value of serum hCG on the outcome of pregnancy of unknown location: a systematic review and metaanalysis. Hum Reprod Update. 2012;18(6):603-17.

9. Bignardi T, Alhamdan D, Condous G. Is ultrasound the new gold standard for the diagnosis of ectopic pregnancy? Semin Ultrasound CT MR. 2008;29(2):114-20.

10. Trio D, Strobelt N, Picciolo C, Lapinski RH, Ghidini A. Prognostic factors for successful expectant management of ectopic pregnancy. Fertil Steril. 1995;63(3):469-72.

11. Dhar H, Hamdi I, Rathi B. Methotrexate treatment of ectopic pregnancy: experience at Nizwa Hospital with literature review. Oman Med J. 2011;26(2):948.

12. Mooij R, Mgalega GC, Mwampagatwa IH, van Dillen J, Stekelenburg J. A cohort of women with ectopic pregnancy: challenges in diagnosis and management in a rural hospital in a low-income country. BMC Preg Childbirth. 2018;18(1):159.

13. van Mello NM, Mol F, Ankum WM, Mol BW, van der Veen F, Hajenius PJ. Ectopic pregnancy: how the diagnostic and therapeutic management has changed. Obstet Gynecol Surv. 2013;68(2):110-2.

14. Lund J. Early ectopic pregnancy -comments on conservative treatment. J Obstet Gynecol Br Empire. 1955;62:70-6.

15. Elson J, Tailor A, Banerjee S, Salim R, Hillaby K, Jurkovic D. Expectant management of tubal ectopic pregnancy: prediction of successful outcome using decision tree analysis. Ultrasound Obstet Gynaecol. 2004;23:552-6.

16. Korhonen J, Stenman UH, Ylöstalo P. Serum human chorionic gonadotropin dynamics during spontaneous resolution of ectopic pregnancy. Fertil Steril. 1994;61:632-6.

17. Kirk E, Van Calster B, Condous G, Papageorghiou AT, Gevaert O, Van Huffel S, et al. Ectopic pregnancy: using the hCG ratio to select women for expectant or medical management. Acta Obstet Gynecol Scand. 2011;90:264-72.

18. Lipscomb GH. Medical therapy for ectopic pregnancy. Semin Reprod Med. 2007;25(2):93-8.

19. Mahboob U, Mazhar SB. Management of ectopic pregnancy: a two-year study. J Ayub Med Coll Abbottabad. 2006;18(4):34-37.

20. Mavrelos D, Nicks H, Jamil A, Hoo W, Jauniaux E, Jurkovic D. Efficacy and safety of a clinical protocol for expectant management of selected women diagnosed with a tubal ectopic pregnancy. Ultrasound Obstet Gynecol. 2013;42:102-7.

21. Cacciatore B, Korhonen J, Stenman UH, Ylostalo P. Transvaginal sonography and serum hCG in monitoring of presumed ectopic pregnancies selected 
for expectant management. Ultrasound Obstet Gynecol. 1995;5:297-300.

22. Atri M, Chow CM, Kintzen G, Gillett P, Aldis AA, Thibodeau M, Reinhold C, Bret PM. Expectant treatment of ectopic pregnancies: clinical and sonographic predictors. AJR Am J Roentgenol. 2001;176:123-7.

23. Hajenius P, Engelsbel S, Mol BWJ, Van der Veen F, Ankum W, Bossuyt PMM, et al. Randomised trial of systemic methotrexate versus laparoscopic salpingostomy in tubal pregnancy. Lancet. 1997;350:774-9.
24. Kumar V, Gupta J. Tubal ectopic pregnancy. BMJ Clin Evid. 2015;2015:1406.

Cite this article as: Arshad S, Andeel S, Asghar S, Hafeez S, Asghar S, Fatima N. Comparison of outcome in medical versus expectant management in unruptured tubal pregnancy with $\beta$-hCG 1000-3000 IU/L. Int J Reprod Contracept Obstet Gynecol 2020;9:2239-43. 